\title{
The Long-term Personal and Professional Impacts of Participating in a Study Abroad Program
}

\author{
Don DeGraaf \\ Calvin College \\ Cynthia Slagter \\ Calvin College \\ Kelly Larsen \\ New Horizons Foundation, Romania
}

\section{Elisa Ditta}

Association for a More Just Society, Honduras

\section{Introduction}

Something hidden. Go and find it. Go and look beyond the ranges - something lost... and waiting for you.

Rudyard Kipling's words portray perfectly the wonder of studying abroad for many college students. The excitement that leads up to a new adventure in an unknown place invites students into exploration and new experiences. But Kipling's quote also leads one to wonder what is waiting for students after a study abroad experience. What are the short-term and long-term impacts of studying abroad?

The last two decades have witnessed an explosion of semester abroad programs sponsored by colleges and universities in the United States. Promotion of these programs usually includes the touting of a students' time abroad as a life-changing experience, one that will impact them forever. Yet despite these many claims, few empirical studies have moved beyond examining the immediate impacts of studying abroad to examine the long-term impact of the experience on students through a variety of lenses (Dwyer, 2004). Thus, the purpose of this study is twofold. First, the study will compare various measures of civic engagement between students who have and have not completed a semester abroad. Second, the study will examine the long-term personal impacts of studying abroad on students after spending at least one semester off-campus.

\section{Literature Review}

Over the last 20 years, a number of empirical studies have attempted to measure the short-term personal changes in semester abroad participants. Most of these studies link studying abroad to 
significant personal changes in attitude, intercultural and international awareness, self-efficacy and independence, and other markers of personal growth (Black \& Duhon 2009; Carlson 1988; Hammer \& Hansel 2005; Kisantas 2009). While earlier studies demonstrated less positive changes, these studies reported that students who studied abroad actually demonstrated decreased selfconfidence upon their return (Juhasz 1987; Nash 1976). Despite this discrepancy, the bulk of shortterm studies offer glowing reports of life-changing experiences for students who studied abroad.

There are far fewer long-term studies examining the impact of study abroad programs and these studies are more moderate in their claims about the long-term impacts of study abroad. Yet, results still indicate there are positive long-term impacts of study abroad experiences. In 2009, the Study Abroad for Global Engagement (SAGE) examined the "near-term and long-term impact of study abroad on alumni's global engagement, charitable contributions, professional development, and personal development, as perceived by the alumni themselves and as assessed by external measures" (Paige, Fry, Stallman, Josic, \& Jon, 2009, p. S31).

Researchers in the SAGE study measured civic commitments, knowledge production, philanthropy, social entrepreneurship, voluntary simplicity, future education, and occupation experiences through surveys and interviews with thousands of study abroad alumni from various institutions. Results from these self-reported sources found a strong influence on these factors as a result of studying abroad experiences (Paige et al, 2009). However, the study lacked a control group with which to compare its results. This is a common limitation of study abroad research as many studies report significant personal and lifestyle changes in study abroad alumni after their experience overseas, but without a comparable control group, it is a struggle to establish causality (Dukes 1994; Akande 2000; Alred \& Bryan 2002; Armstrong 1984; Bachner \& Zeutschel 2009; Black \& Duhon 2009; Dwyer 2004; Hutchins 1996).

A 2008 study completed by the American Field Service (AFS) addressed this gap by comparing study abroad alumni with their peers over a twenty year span. This study was a continuation of an earlier report in which former AFS participants were shown to exhibit more "intercultural sensitivity" than peers who did not travel abroad (Hammer, 2005). The new report examined the longevity of that demonstrated difference, examining whether the gap between study abroad participants and non-study abroad participants narrowed later in life (Hansel, 2008). Utilizing a wide-ranging survey of alumni from 20 to 25 years prior, as well as a large control group of former peers to those alumni, the AFS study found a connection between studying abroad and many behavioral and attitudinal variables.

The most prominent direct connection between the study abroad experience and a measurable variable was found in the ability to speak another language. In addition, study abroad alumni were more likely to have friends from other cultures, to be more likely to work with other cultures professionally, to exhibit lower levels of intercultural anxiety, and to encourage their children to study abroad than their former peers, even over two decades after the alumni's experience abroad (Hansel, 2008).

Similarly, Hadis (2005) reported that study abroad alumni were more interested in international affairs, read newspapers more often than before going abroad, increased their fluency in other languages, and acquired a more solid knowledge about their host countries' societies and cultural manifestations. Hadis also noted significant personal development in the subjects, who emerged 
from their experiences abroad more independent, more outgoing, more friendly toward people from other countries, more self-assured and uninhibited about traveling to countries where English is not the first language.

Moving beyond the attitudinal and relational benefits of studying abroad, Benson-Schrambach (2009) examined professional development resulting from educational experiences overseas. Results of this study indicated that a semester abroad did have a strong impact on students' professional development; however this impact varied based on the amount of time that had elapsed since the experience. Alumni who had studied abroad further in the past saw their experience abroad affecting their vocational direction more than alumni who had studied abroad more recently. In a similar study, Allen (2010) analyzed the impact of a summer institute in France on the personal and professional lives of French teachers. Results of the study indicated that the experience was an effective professional development tool, leading teachers to change their curriculum and instructional practices in the classroom.

Despite the clear evidence of the significance of studying abroad in alumni's lives, questions remain. For example, is the study abroad experience the cause of these changes or are students who go on study abroad experiences already predisposed to these developmental and lifestyle changes (Gonyea, 2008)? Similarly, does the location where a student studies have a significant impact on the experience? As Hutchins (1996) reported, the location of the student's experience has a significant bearing on the impacts of the overall experience. In particular, study locations in the global North (primarily Europe) and in the global South (Latin America, Africa, etc.) differ significantly in the outcomes reported by students. Both of these questions demand further examinations moving forward.

\section{Research Questions and Methodology}

The research questions for this study are divided into two broad queries. First, what are the effects of a semester abroad on alumni's civic engagement? Second, what are the long-term impacts (personal and professional) of a semester abroad?

Students from a small, liberal arts college in the Midwest served as the pool of subjects for this study, conducted in the summer of 2009. This college was chosen because of the large number of students who have studied abroad over the past twenty years, and because of the school's excellent records, which enabled researchers to track present addresses of potential subjects.

Twelve hundred $(1,200)$ subjects were asked to complete an on-line survey. Approximately half the subjects had spent a semester abroad in the past twenty years (between 1986 and 2007), while the other half had not.

A total of 354 respondents completed the questionnaire, yielding a $29.5 \%$ response rate. Of these respondents, 193 had studied off-campus for a semester and 141 had not. Of the 193 respondents who studied off-campus, 180 respondents studied abroad while the remaining 13 respondents participated in a semester program with the Navajo Nation in New Mexico. Although these 13 participants studied within the United States, the Navajo Nation has sovereignty as a domestic dependent nation, thus providing many of the same cross-cultural experiences of a study abroad experience. Table 1 presents the overall characteristics of the respondents who had studied 
abroad for at least a semester as they relate to the dependent variables of the study (gender, major, and years since studying abroad).

TABLE 1: DEMOGRAPHICS OF RESPONDENTS WHO HAD STUDIED ABROAD (N=193)

\begin{tabular}{|c|c|c|c|c|c|}
\hline $\begin{array}{l}\text { Gender } \\
\mathrm{n}=191\end{array}$ & \multicolumn{3}{|l|}{$\begin{array}{l}\text { Male: } \\
71(37.2 \%)\end{array}$} & \multicolumn{2}{|c|}{$\begin{array}{l}\text { Female: } \\
120(62.8 \%)\end{array}$} \\
\hline $\begin{array}{l}\text { Time } \\
\text { elapsed } \\
n=188\end{array}$ & \multicolumn{3}{|c|}{$\begin{array}{l}\text { Less than } 10 \text { years: } \\
109(58.0 \%)\end{array}$} & \multicolumn{2}{|c|}{$\begin{array}{l}10 \text { years or longer: } \\
79(42.0 \%)\end{array}$} \\
\hline $\begin{array}{l}\text { Major } \\
n=126\end{array}$ & $\begin{array}{l}\text { Business: } \\
17(13.4 \%)\end{array}$ & $\begin{array}{l}\text { Education: } \\
28(22.2 \%)\end{array}$ & $\begin{array}{l}\text { English: } \\
23(18.3 \%)\end{array}$ & $\begin{array}{l}\text { Sociology or } \\
\text { Social Work: } \\
21(16.7 \%)\end{array}$ & $\begin{array}{l}\text { Spanish: } \\
37(29.4 \%)\end{array}$ \\
\hline
\end{tabular}

Notes: 1. Variance in $\mathrm{n}$ values results from participants' self-identification on survey. Complete demographic information was not submitted by all respondents. 2. Of the 193 participants, thirteen participated in a semester program with the Navajo Nation in New Mexico.

In examining the first research question (related to civic engagement), the on-line survey built on the work of the 2009 SAGE study and conceptualized civic engagement as: civic commitment in both the domestic and international arenas; staying current with events on a local and global scale; philanthropy in terms of volunteering time and monetary donations; and the practice of voluntary simplicity in one's lifestyle (Paige et al, 2009). Results were compared to determine if students who had spent a semester abroad where more civically engaged then students who did not.

In examining the second research question (related to personal impacts of a semester abroad), study abroad alumni were asked about their individual development and maturation, particularly regarding self-confidence and intercultural awareness as a result of their time abroad. In addition, they were also asked about their vocational direction and professional development as impacted by their time abroad. This on-line survey was supplemented with qualitative data taken from individual interviews.

Respondents who had studied abroad were asked if they would be willing to be interviewed by the researchers. For those who agreed to be interviewed, a purposive sampling method was used based on two variables: location of study abroad experience and number of years elapsed since that experience. These variables divided respondents into 15 groups. Within each of these groups, two members were randomly selected and contacted for an interview. Of the 30 randomly selected participants, 26 agreed to participate in the interview process.

Surveys were analyzed using two different statistical processes, Chi Square and one-way analysis of data (ANOVA). For research questions where the independent variable had only two categories (e.g. gender), Chi Square was used to determine any statistically significant difference. For research questions where the independent variables had more than two categories (e.g. academic major), ANOVA was used to determine any statistically significant difference. For all survey results, statistical significance was determined at a 95 percent level.

\section{Results and Discussion}

Results were analyzed separately for each of the two broad research questions. This section presents the results of the study of these two research questions: (1) What are the effects of a 
semester abroad on alumni's civic engagement? (2) What are the long-term impacts (personal and professional) of a semester spent studying abroad?

\section{Impact of the study abroad experience on civic engagement}

The effect of studying abroad on respondents' level of civic engagement was measured and compared to peers who did not study abroad for a semester. The level of civic engagement (both locally and internationally) was measured through responses to indicator questions related to how often respondents volunteered in the community, connected to local news, donated blood, were active in neighborhood associations, etc. Results indicated that students who did study abroad for a semester were more civically engaged than respondents who did not study abroad. Specifically, there were eight behaviors where respondents who did study abroad were significantly more likely to be involved in their local communities or in global issues (see Tables 2, 3, and 4).

TABLE 2: LOCAL CIVIC ENGAGEMENT

\begin{tabular}{|l|l|l|}
\hline & $\begin{array}{l}\text { Studied Abroad } \\
(\mathrm{n}=193)\end{array}$ & $\begin{array}{l}\text { No Study Abroad } \\
(\mathrm{n}=141)\end{array}$ \\
\hline Utilize a form of public transportation, carpool, or bike & $\mathbf{7 1 . 0 \%}$ & $\mathbf{4 2 . 0 \%}$ \\
\hline Read/listen/watch local news & $88.5 \%$ & $93.6 \%$ \\
\hline Attend/lead a book club & $17.3 \%$ & $18.8 \%$ \\
\hline Volunteer in a local school & $27.0 \%$ & $30.7 \%$ \\
\hline Volunteer in local non-profit organization & $51.3 \%$ & $51.4 \%$ \\
\hline Donate blood & $43.2 \%$ & $42.3 \%$ \\
\hline Intentionally purchase locally-made products & $\mathbf{7 9 . 8 \%}$ & $\mathbf{7 0 . 7} \%$ \\
\hline Shop at a farmer's market & $\mathbf{6 0 . 1 \%}$ & $\mathbf{4 7 . 5 \%}$ \\
\hline
\end{tabular}

Notes: 1. Percentage indicates respondents who marked "frequently" or "occasionally" (remaining respondents marked "rarely" or "never") to a question of how often they engaged in the above activities. Statistically-significant differences (measured at .05) are marked in bold. 2. Of the 193 participants 13 participated in a semester program with the Navajo Nation in New Mexico.

TABLE 3: LOCAL CIVIC ENGAGEMENT

\begin{tabular}{|l|l|l|}
\hline & $\begin{array}{l}\text { Studied Abroad } \\
(n=193)\end{array}$ & $\begin{array}{l}\text { No Study Abroad } \\
(n=141)\end{array}$ \\
\hline Organized or signed a petition & $71.5 \%$ & $67.6 \%$ \\
\hline Voted in an election & $96.8 \%$ & $95.0 \%$ \\
\hline Been involved in protests or demonstrations & $\mathbf{3 2 . 0 \%}$ & $\mathbf{1 9 . 3 \%}$ \\
\hline Written a letter to the editor & $22.3 \%$ & $19.3 \%$ \\
\hline Contacted or visited a public official & $59.6 \%$ & $52.1 \%$ \\
\hline Been a member of a CSA & $\mathbf{1 7 . 2 \%}$ & $\mathbf{7 . 1 \%}$ \\
\hline Been active in a neighborhood association & $\mathbf{3 5 . 4 \%}$ & $\mathbf{3 4 . 3 \%}$ \\
\hline Hosted an exchange student & $5.7 \%$ & $\mathbf{7 . 1 \%}$ \\
\hline Served as a mentor & $53.7 \%$ & $53.2 \%$ \\
\hline
\end{tabular}

Notes: 1. Percentage indicates respondents who reported engaging in the above activities in the past five years. Statistically-significant differences (measured at .05) are marked in bold. 2. Of the 193 participants, thirteen participated in a semester program with the Navajo Nation in New Mexico. 


\begin{tabular}{|l|l|l|}
\hline & $\begin{array}{l}\text { Studied Abroad } \\
(\mathrm{n}=193)\end{array}$ & $\begin{array}{c}\text { No Study Abroad } \\
(\mathrm{n}=141)\end{array}$ \\
\hline Volunteering for organization outside of home country & $28.6 \%$ & $20.7 \%$ \\
\hline Read/listen/watch international news & $\mathbf{8 9 . 1 \%}$ & $\mathbf{8 0 . 7 \%}$ \\
\hline Pray about events occurring around the world & $78.1 \%$ & $82.1 \%$ \\
\hline Attend events of a culture different from my own & $\mathbf{4 2 . 7 \%}$ & $\mathbf{2 5 . 7 \%}$ \\
\hline Spend free time with people from a different culture & $\mathbf{7 0 . 5 \%}$ & $\mathbf{5 2 . 1 \%}$ \\
\hline
\end{tabular}

Notes: 1. Percentage indicates respondents who marked "frequently" or "occasionally" (remaining respondents marked "rarely" or "never") to a question of how often they engaged in the above activities. Statistically-significant differences (measured at .05) are marked in bold . 2. Of the 193 participants, thirteen participated in a semester program with the Navajo Nation in New Mexico.

Many of these differences are logical. It is not surprising that respondents who spent significant amounts of time in another culture, developing relationships with people from around the world, are more likely to maintain those relationships and interests upon their return and continue to invest in people and issues from other parts of the world. It is interesting to note that some of the measures of local civic engagement which emerged more strongly in the results of study abroad alumnishopping locally, using public transportation, supporting local agriculture-are less obvious results of time spent overseas. It may be possible that these inclinations emerge from students' desire to model their lifestyle in the United States after the habits they engaged in while in another culture, these behaviors included shopping at local markets, living close to the land, and riding public transportation of various kinds. As one female respondent noted:

My off-campus experience definitely affected, and continues to affect, my life today. After living in a different way, and seeing how others live (in some ways more materialistically simply), I recognize the positive aspects of a different type of life. Examples? Savoring a meal after spending hours cooking - a simple expression of significantly different values that I try to place in my life now, rather than the "hurry up and go" mentality of [the] US, a consumer culture. It made me realize contentedness and connection in people and simpler things. I now prefer a smaller living space in an area where I can walk to local restaurants and be a part of my community- much of this perspective emerged from my living experience in Spain (1990).

As seen in previous studies (Paige, Fry, \& Stallman, Josic, \& Jon 2009; Hadis 2005; Gonyea 2009), there is a demonstrable positive impact on students' civic engagement after studying abroad. However, it is difficult to measure causality or determine whether students who were already more inclined to civic engagement are also those students most likely to study abroad in the first place, or whether the semester abroad is the determining factor of their increased civic engagement. This question, echoing Gonyea's 2009 findings, remains worthy of further research.

\section{Personal and Professional Impacts of the Study Abroad Experience}

After analyzing the differences in ongoing civic engagement between respondents who had and had not studied abroad, the study narrowed its scope to analyzing the long-term personal and professional impact of studying abroad as it related to personal growth, professional development, and attitudinal and behavioral changes. 
The personal impact of a semester abroad on alumni is quite evident — as one female respondent (2005) who studied in Honduras wrote, "Probably one of the single greatest impacts on my life. Changed my world view, what I wanted to do with my life, and how I wanted to live my life." This alumnus' comment was supported and re-stated with great frequency throughout the survey and interview responses by other respondents, and leads to a conclusion which corresponds with existing research that studying abroad has a great impact on students' lives.

In this study, the impact of a semester abroad on an individual's personal life was measured by responses to questions which probed personal changes in mindset/awareness, maturity, lifestyle choices, personal skills, sense of adventure and self-confidence, career choices and development, as well as feelings of independence and self-efficacy. These questions encompassed both attitudinal and behavioral changes, though no objective behavioral observation of respondents could be made. In addition, each question was also analyzed using three variables: gender, academic major, and length of time since studying abroad.

\section{Gender}

Although more women $(n=120)$ completed the on-line survey than men $(n=71)$ this is consistent with the fact that more women study abroad than men at the college. Overall results indicated no statistical significance emerged between men and women related to either attitudes or behaviors following their semester abroad. Complete results appear in Table 5 and Table 6 . The disparity in the number of men and women who study abroad is interesting and merits further study and discussion.

TABLE 5: IMPACT OF STUDYING ABROAD, BY GENDER

\begin{tabular}{|l|l|l|}
\hline & Male $(n=71)$ & Female $(n=120)$ \\
\hline Increased interactive/social skills & $56.3 \%$ & $51.7 \%$ \\
\hline Increased employment/educational opportunities & $31.0 \%$ & $37.5 \%$ \\
\hline Increased intellectual curiosity & $80.3 \%$ & $74.8 \%$ \\
\hline Greater appreciation of other cultures & $77.5 \%$ & $80.8 \%$ \\
\hline Decreased satisfaction with home culture & $15.5 \%$ & $27.5 \%$ \\
\hline Reinforcement/confirmation of existing viewpoints & $16.9 \%$ & $29.4 \%$ \\
\hline Increased cynicism about the world & $8.5 \%$ & $14.3 \%$ \\
\hline Increased appreciation for home culture & $29.6 \%$ & $23.3 \%$ \\
\hline Increased language skills & $56.3 \%$ & $51.7 \%$ \\
\hline Increased knowledge related to major or discipline & $53.5 \%$ & $62.2 \%$ \\
\hline Spiritual growth & $33.8 \%$ & $38.3 \%$ \\
\hline Increased sense of adventure/daring & $63.4 \%$ & $75.0 \%$ \\
\hline Deepened relationships with foreign nationals & $41.4 \%$ & $35.6 \%$ \\
\hline Deepened relationships with faculty & $34.3 \%$ & $35.3 \%$ \\
\hline Deepened relationships with peers & $60.5 \%$ & $60.5 \%$ \\
\hline
\end{tabular}

Notes: 1. Percentage indicates respondents who marked "strong influence" of a semester abroad on the above variables (remaining respondents marked "some influence" or "no influence"). No statistically significant differences (.05) were found. 2. Of the 71 male participants, four participated in a semester program with the Navajo Nation in New Mexico. 3. Of the 120 female participants, nine participated in a semester program with the Navajo Nation in New Mexico. 
TABLE 6: CONTINUED IMPACT OF STUDYING ABROAD, BY GENDER

\begin{tabular}{|l|l|l|}
\hline & Male $(n=71)$ & Female $(n=120)$ \\
\hline Voluntary simplicity & $21.1 \%$ & $29.7 \%$ \\
\hline Occupation or career choice & $36.6 \%$ & $39.0 \%$ \\
\hline $\begin{array}{l}\text { Social entrepreneurship - creating new organizations that have social } \\
\text { objective as its primary goal }\end{array}$ & $9.9 \%$ & $12.9 \%$ \\
\hline Civic engagement: international issues & $31.0 \%$ & $30.5 \%$ \\
\hline Civic engagement: domestic issues & $17.1 \%$ & $16.1 \%$ \\
\hline Philanthropy: volunteer work & $7.1 \%$ & $13.6 \%$ \\
\hline Philanthropy: monetary donations & $15.7 \%$ & $11.9 \%$ \\
\hline Spiritual development & $14.1 \%$ & $22.7 \%$ \\
\hline
\end{tabular}

Notes: 1. Percentage indicates respondents who marked "to a large degree" on questions about the impact of their study abroad semester on present levels of involvement in the above areas (remaining respondents marked "to some degree" or "not at all"). No statistically-significant differences (.05) were found. 2. Of the 71 male participants, four participated in a semester program with the Navajo Nation in New Mexico. 3. Of the 120 female participants, nine participated in a semester program with the Navajo Nation in New Mexico.

\section{Academic major}

The second variable of comparison was major concentration. The academic disciplines most frequently represented in respondents were the following: Spanish $(n=37)$, Education $(n=28)$, English $(n=23)$, Sociology/Social Work $(n=21)$, and Business $(n=17)$. Statistically significant differences between the means of the five predominant majors were found in six areas related to the impact of studying abroad (see Table 7). In each of the areas with statistically significant difference, the variance found was significant among all groups. However, in the discussion to follow, only the maximum and minimum values in each of these categories will be compared, in order to illustrate more simply the possible reasons for differences that emerged in the analysis.

In three areas-increased employment and/or educational opportunities, increased knowledge related to discipline or major, and influence on career choice-Spanish majors had the highest mean response regarding the influence of their semester abroad. Business majors had the lowest mean on the same measures. Reasons for this are deduced from the qualitative data gleaned through interviews, and though somewhat speculative, remain informative. For Spanish majors, the strong impact of a semester abroad on their professional and academic careers is logical. As Allen's 2009 study demonstrated, experience abroad has an invigorating and deepening effect on foreign language teachers, which then manifests itself in obvious ways in their future study and teaching. 
TABLE 7: IMPACT OF STUDYING ABROAD, BY MAJOR

\begin{tabular}{|c|c|c|c|c|c|}
\hline & $\begin{array}{l}\text { Spanish } \\
(n=37)\end{array}$ & $\begin{array}{l}\text { Education } \\
(n=28)\end{array}$ & $\begin{array}{l}\text { English } \\
(n=23)\end{array}$ & $\begin{array}{l}\text { Soc./Soc. Wk. } \\
(n=21)\end{array}$ & $\begin{array}{l}\text { Business } \\
(n=17)\end{array}$ \\
\hline Increased interactive/social skills & 2.62 & 2.61 & 2.48 & 2.48 & 2.53 \\
\hline $\begin{array}{l}\text { Increased } \\
\text { employment/educational } \\
\text { opportunities }\end{array}$ & 2.49 & 2.29 & 1.91 & 2.05 & 1.88 \\
\hline Increased intellectual curiosity & 2.81 & 2.7 & 1.91 & 2.57 & 2.65 \\
\hline $\begin{array}{l}\text { Greater appreciation of other } \\
\text { cultures }\end{array}$ & 2.73 & 2.93 & 2.78 & 2.71 & 2.71 \\
\hline $\begin{array}{l}\text { Decreased satisfaction with home } \\
\text { culture }\end{array}$ & 1.86 & 2.00 & 1.78 & 2.14 & 1.56 \\
\hline $\begin{array}{l}\text { Reinforcement/confirmation of } \\
\text { existing viewpoints }\end{array}$ & 2.03 & 1.79 & 1.87 & 1.95 & 2.06 \\
\hline $\begin{array}{l}\text { Increased cynicism about the } \\
\text { world }\end{array}$ & 1.49 & 1.54 & 1.43 & 1.57 & 1.12 \\
\hline $\begin{array}{l}\text { Increased appreciation for home } \\
\text { culture }\end{array}$ & 2.08 & 2.04 & 1.78 & 1.90 & 2.18 \\
\hline Increased language skills & 2.95 & 2.64 & 1.96 & 2.00 & 2.41 \\
\hline $\begin{array}{l}\text { Increased knowledge related to } \\
\text { major or discipline }\end{array}$ & 2.89 & 2.64 & 2.52 & 2.15 & 2.05 \\
\hline Voluntary simplicity & 1.86 & 1.74 & 1.83 & 2.95 & 1.56 \\
\hline Occupation or career choice & 2.43 & 2.18 & 2.09 & 2.00 & 1.71 \\
\hline Social entrepreneurship & 1.73 & 1.74 & 1.65 & 1.48 & 1.56 \\
\hline Civic engagement: international & 1.95 & 1.85 & 2.09 & 1.95 & 1.59 \\
\hline Civic engage ment: domestic & 1.62 & 1.62 & 1.61 & 2.10 & 1.56 \\
\hline Philanthropy: volunteer work & 1.70 & 1.70 & 1.78 & 1.76 & 1.47 \\
\hline Philanthropy: monetary donations & 1.73 & 1.63 & 1.70 & 1.60 & 1.41 \\
\hline Spiritual development & 1.97 & 1.96 & 2.13 & 1.86 & 1.59 \\
\hline
\end{tabular}

Notes: 1. Number indicates the mean response based on the following scale: 3=To a large degree; 2=To some degree; 1=Very little or not at all. 2. Six of the Education majors and two of the Social Work majors participated in the semester program with the Navajo Nation in New Mexico

The real-world experience of Spanish majors in the college's programs in Honduras and Spain gave them more opportunity to achieve fluency beyond the classroom, and these experiences yielded significant and obvious benefits upon their return. As one male alumnus (1986) from Spain explained, "Experiential learning is... going over to Spain for four months. That's experiential learning....You're not going to get that out of a textbook." Similarly a 1990 alumnus from Spain noted: "I don't know if I would have made the choice to be a Spanish major if I hadn't had that well-rounded of an experience-if it had been merely academics... just on a practical level, if I hadn't gone to Spain and then back again, I wouldn't have been able to do graduate level work in the Spanish language."

Business majors, however, reported seeing fewer direct effects of a study abroad semester in their professional lives. Some of this difference may stem from the sort of programs offered by the college. Although there is the opportunity to take a business class or two in some programs, there are no semester programs that focus exclusively on business. This may have contributed to the perception that the semester had less of an impact on employment opportunities and career paths.

Despite this finding, specific respondents (who were business majors) did identify the overall benefit of a semester abroad. One respondent (2002) who studied in Hungary and now works in Washington D.C. noted that he had listed his experience abroad as a professional development experience on resumes, and that the flexibility and global perspective it developed in him has been 
profoundly beneficial in his career path. Another male respondent (2004) who studied in China stated, "changing my mindset, broadening my horizons, broadening my perspectives: it definitely had a pretty big impact on me... it had sort of a maturing influence on me that was important both personally and professionally." Throughout the study the clear value of the semester abroad is evident in alumni's lives, though some variability emerges in its direct professional and educational impact based on the student's academic discipline.

Other areas of statistically significant disparity emerged in the variables of increased intellectual curiosity and increased language skills. On these two variables, Spanish majors again reported the greatest average impact from their semester abroad. English majors were the respondents with the lowest reported mean impact. It is not surprising that Spanish majors immersed in a Spanishspeaking country find themselves flourishing academically. Language skills-both fluency and comfort-increase dramatically in an immersion situation (Allen, 2010), and for students who love the language and culture enough to pursue a Spanish degree in college, a semester abroad is an excellent chance to fan the flames of intellectual curiosity. Thus, as survey and interview results clearly demonstrated, it is common for a semester abroad to strongly impact Spanish majors in terms of increasing their language skills as well as fueling their intellectual curiosity. This impact can be seen in the comment of a Spain semester alumnus (1990), who stated "it really, really broadened my horizons. And I think that was very significant for me both on a personal and professional level."

The reasons for lower mean scores among English majors on these same variables (intellectual curiosity and language skills) are less clear-cut. Most English major studied in Britain, which has virtually no opportunity to learn a new language. This diminished emphasis on other languages may have contributed to this difference as the survey data demonstrated that $41.9 \%$ of English majors who studied abroad self-reported their own second language skills as "poor," and 61.3\% of English majors said that the desire to learn another language had no influence or was not applicable to their choice to study abroad.

In terms of intellectual curiosity, the reason for the discrepancy between the academic disciplines, particularly Spanish and English majors, is less intuitive. It could relate to the direct correlation between Spanish majors' academic interests and the location of their semester abroad, a link that may have been less direct for English majors. Regardless of the cause of the lower score for some majors on the impact of study abroad on intellectual curiosity and increased language skills, it is still evident that the overall experience continued to have a significant impact on respondents in terms of how respondents saw and engaged the world. As one male, English major (1999) noted:

Without my off-campus experience, much in my life would have been different (and likely much less rich). Staying at an Anglican seminary taught me to love liturgical worship, a path I've followed. Sampling the food available in Britain and Europe opened my taste buds to a variety of world cuisines, which made me come to dislike processed foods and appreciate the fresh and local whenever possible. The experience opened the door (in a non-threatening way, since it was England) to understanding other cultures and seeing, understanding, and appreciating both the US and other cultures and their people more clearly, which has opened up my heart to the world. I'm profoundly thankful for the large part the Semester in England played on that path. 
Finally, in the measurement of the effect of a semester abroad on a student's commitment to voluntary simplicity, statistically significant differences were found between sociology and social work majors, who reported the greatest mean impact, and business majors, who reported the lowest average impact. For the sake of this study, voluntary simplicity was viewed as the effort to lead a more modest, simple lifestyle (e.g. recycling, riding a bike to work, or taking a job that pays less but contributes more to the common good).

Given this definition, it is not surprising that respondents who had majored in sociology or social work would place a great deal of importance on this variable. In addition, the work of Hutchins (2009) indicates that location of the study abroad semester has a large impact on how the experience shapes students. In the case of this study the majority of business majors studied in the developed world, while the majority of social work/sociology majors studied in the developing world. In many ways, it makes sense that students who studied in developing countries see the importance of living simply when they return.

A second possible cause emerges from the difference in the two groups' experiences with servicelearning and/or volunteering while studying abroad. Only $23.8 \%$ of business majors participated in any form of service-learning while on their semester abroad, while a full $50 \%$ of sociology/social work majors did so. Sociology/social work majors were also much more likely to have a job shadowing or internship component in their experience abroad than business majors, and were more likely to take classes with local students than business majors. As one female, sociology/social work major who studied in China (1998) wrote in the survey comments, "Every student should go abroad sometime in their academic career. We all need to know how others live.” Personal interactions with people around the world are likely to motivate and challenge students to make personal changes in their own lifestyle and mindset. Location, service, and local interaction varied among semester programs, and it is possible that business students may have participated in semesters where such experiences occurred less frequently than sociology and social work majors.

\section{Length of time elapsed since study abroad experience}

The third independent variable examined in this study was length of time elapsed since the respondents' study abroad experience. This comparison examines the long-term effects of studying abroad by separating respondents into two categories: "short-term" (less than ten years since studying abroad) and "long-term" (ten or more years since studying abroad). Results of this analysis can be found in Table 8 and Table 9 and indicates there are eight attitudes or behaviors where a significant difference can be seen between these two groups. In all eight, short-term respondents indicated a significantly stronger influence from their study abroad semester on their attitudes or behavior then respondents who are more than ten years removed from the experience. 
TABLE 8: IMPACT OF STUDYING ABROAD, BY LENGTH OF TIME SINCE EXPERIENCE ABROAD

\begin{tabular}{|l|l|l|}
\hline & $\begin{array}{l}\text { Less than 10 years } \\
(n=109)\end{array}$ & $\begin{array}{l}10 \text { or more years } \\
(n=79)\end{array}$ \\
\hline Increased interactive/social skills & $62.4 \%$ & $58.2 \%$ \\
\hline Increased employment/educational opportunities & $43.1 \%$ & $25.3 \%$ \\
\hline Increased intellectual curiosity & $76.2 \%$ & $78.2 \%$ \\
\hline Greater appreciation of other cultures & $81.6 \%$ & $76.0 \%$ \\
\hline Decreased satisfaction with home culture & $25.7 \%$ & $20.3 \%$ \\
\hline Reinforcement/confirmation of existing viewpoints & $22.0 \%$ & $29.5 \%$ \\
\hline Increased cynicism about the world & $19.3 \%$ & $4.0 \%$ \\
\hline Increased appreciation for home culture & $22.9 \%$ & $30.4 \%$ \\
\hline Increased language skills & $53.2 \%$ & $53.2 \%$ \\
\hline Increased knowledge related to major or discipline & $65.7 \%$ & $50.6 \%$ \\
\hline Spiritual growth & $38.5 \%$ & $36.7 \%$ \\
\hline Increased sense of adventure/daring & $67.0 \%$ & $76.0 \%$ \\
\hline Deepened relationships with foreign nationals & $44.9 \%$ & $27.0 \%$ \\
\hline Deepened relationships with faculty & $40.7 \%$ & $19.2 \%$ \\
\hline Deepened relationships with peers & $68.5 \%$ & $46.2 \%$ \\
\hline Notes: & \\
\hline
\end{tabular}

Notes: 1. Percentage indicates respondents who marked "strong influence" of semester abroad on the above variables (remaining respondents marked "some influence" or "no influence"). Statistically-significant differences (.05) are marked in bold. 2. Ten participants who were less than 10 years removed from the experience participated in a semester program with the Navajo Nation in New Mexico; three participants who were more than 10 years removed from the experience participated in a semester program with the Navajo Nation in New Mexico.

TABLE 9: CONTINUED IMPACT OF STUDYING ABROAD, BY LENGTH OF TIME SINCE EXPERIENCE ABROAD

\begin{tabular}{|l|l|l|}
\hline & $\begin{array}{l}\text { Less than 10 years } \\
(n=109)\end{array}$ & $\begin{array}{l}10 \text { or more years } \\
(n=79)\end{array}$ \\
\hline Voluntary simplicity & $\mathbf{3 5 . 2 \%}$ & $\mathbf{1 5 . 4 \%}$ \\
\hline Occupation or career choice & $44.4 \%$ & $29.5 \%$ \\
\hline Social entrepreneurship & $14.2 \%$ & $10.3 \%$ \\
\hline Civic engagement: international issues & $\mathbf{4 0 . 7 \%}$ & $\mathbf{1 8 . 0 \%}$ \\
\hline Civic engagement: domestic issues & $\mathbf{2 2 . 2 \%}$ & $\mathbf{9 . 1 \%}$ \\
\hline Philanthropy: volunteer work & $15.7 \%$ & $6.4 \%$ \\
\hline Philanthropy: monetary donations & $16.7 \%$ & $9.0 \%$ \\
\hline Spiritual development & $23.2 \%$ & $16.5 \%$ \\
\hline
\end{tabular}

Notes: 1. Percentage indicates respondents who marked "to a large degree" on questions about the impact of their study abroad semester on present levels of involvement in the above areas (remaining respondents marked "to some degree" or "not at all"). Statistically-significant differences (.05) are marked in bold. 2. Ten participants who were less than 10 years removed from the experience participated in a semester program with the Navajo Nation in New Mexico; three participants who were more than 10 years removed from the experience participated in a semester program with the Navajo Nation in New Mexico.

Again, it is not surprising that respondents closer to the actual experience would report being more influenced in many of these areas. For example, respondents who graduated more recently may be closer to landing their first career opportunity resulting in remembering a greater impact on the job search process. Similarly, in the ever-increasing complexity of today's global marketplace, international experience may be more of a valuable asset on a resume for many jobs, in a way that it was not even ten years ago. Thus, the variance in responses to this question may be an indicator of globalization's ever-growing effect. As one male respondent from Hungary (2002) noted, "I have a lot of offers for different jobs; I think a lot of it had to do with my international background... when 
they look on my resume and see all the places I've been and some of the things I've done while abroad... it's been advantageous."

A second interesting point of comparison emerges in the categories of deepened relationships with foreign national, faculty, and peers. In each of these categories, students who studied abroad in the last ten years reported significantly higher influence of their study abroad experiences in developing relationships. The most obvious reason for these findings may simply be memory. Alumni who studied abroad more than a decade ago are likely to have moved on to other places and other relationships, and the strength of former relationships from their semester abroad is likely to have become a distant memory.

The value of building relationships while studying abroad was also reinforced in many of the follow-up interviews. As one female respondent (2000) wrote, "The semester abroad group of students continued to frequently get together. Because of this, my interest in China continued to grow through conversations and intellectual stimulation. These gatherings did help prolong the influence of the off-campus study." This sentiment was echoed over and over in the interviews, with comments like I maintained friendships with members and international friends for quite a few years. This was helpful, and I continued to meet with students from the program as friends for years! These comments demonstrate that a semester abroad does influence peer-to-peer relationships positively, and that those relationships play an important role in students' experiences while abroad and after returning home.

A third area where differences were found between short-term and long term respondents is the effect of the semester abroad on their civic engagement. Here, the differences are rather striking: $40.7 \%$ of short-term alumni report a large impact from their time abroad on their current international civic engagement, compared to only $18 \%$ of long-term alumni. Similarly, $22.2 \%$ of short-term alumni reported a large impact from their time abroad on their current local civic engagement, compared to only $9.1 \%$ of the long-term alumni group. Again, theories about this discrepancy are merely speculative, perhaps related once again to length of time since returning and a more complete readjustment to life in the home country. Another possibility could be that respondents returning over ten years ago have incorporated many of these values into their current lifestyles for so long that they no longer think of the original impetus for that engagement being their semester abroad. These speculations, however, are not clearly supported by any evidence, and remain a point of necessary consideration and further discussion.

\section{Why Study Abroad?}

In addition to examining the personal and professional benefits to a study abroad experience, the qualitative portion of the study also looked at the study abroad experience itself. During the thirty in-depth interviews with respondents, they were asked to respond to open ended questions centered on why they decided to study abroad, what factors impacted the overall quality of the experience, and what were the long-term impacts of the study abroad semester?

Three themes emerged related to the factors that encouraged respondents to study abroad. These themes centered on major and minor requirements (especially language), the fact the experience was a unique opportunity at a good point in their lives, and the overall adventure and exploration related to the semester. 
Within these three themes, interviews reinforced the notion that the opportunity to study abroad appealed to planners as well as spontaneous individuals. Several students talked about the reason they came to the college was for the many opportunities offered to study abroad. These individuals often planned their college career around one or two study abroad semesters. For other students, studying abroad developed almost spontaneously, consider one male respondent (2003) who noted: "I woke up one day feeling sick of Grand Rapids because I grew up here, so I went to the off-campus programs office and they said they had space in Hungary and in Ghana, and I thought about it and I had a couple friends who were going to Hungary and was like, "I don't want to go to Europe, which is more or less like our culture, in a lot of ways", so I took the plunge and went to Ghana with eight people I didn't know."

In encouraging students to study abroad, administrators must be ready to help both types of students. From providing extensive materials to help students plan their time abroad to also being available to students to talk about the possibilities and encouraging and challenging students to take advantage of the opportunities available. However, beyond understanding the varied motivations of students it is also important to recognize the factors that impact the overall experience in a positive way. In this way, programs can be designed with these factors in mind.

\section{Factors (Components) that Impacted the Overall Quality of the Experience}

In discussing the factors that impacted the overall semester abroad, respondents focused exclusively on the factors that positively contributed to the experience. The themes that emerged included the internal dynamics of the group (friendships with peers), the professor/director of the program, the culture/community where the program was located, independent travel, and friendships made with host-country nationals (see table 10).

These themes contribute to two tensions that are often evident in the study abroad experience. The first tension relates to the importance of both the internal group dynamics of the experience as well as the need to push students to engage the people and culture of the area where the program is offered. As one male respondent (2005) noted "in Honduras the internal group dynamic was fantastic, we had an excellent group and we just all meshed and got close to one another, so that was a highlight." Contrast this to the male respondent (also from Honduras, 2005) who noted that his "highlights were always with my host family... I became a part of the family."

Likewise, many students noted both the internal group dynamics and the host nationals they met. As one male student (2006), summarized "The whole experience was very memorable; it was probably the best time of my life. Like all the people that I went with were amazing, and then I met so many other people, like other international students and also people from Ghana. I still talk with most of them, I was actually just talking with my roommate who's from Ghana, like 20 minutes ago on Facebook."

The tension between the internal group and engaging the "other" was a consistent theme throughout the interviews, thus reminding study abroad professionals that both of these components are important and need to be managed and balanced. Similarly the second tension revolves around the opportunities that students have to travel independently during the semester but also the desire for programs to help students develop a sense of place and rootedness to the places where they study. 
Respondents in this study noted the importance of independent travel, "I think one of the things that really was extremely important for my learning experience on this particular semester was that we did do a lot of outside travel, and we went all over the place, both for class as well as just sort of for fun" (female, Hungary, 2007). This love of travel was also balanced with the realization that the study abroad experience can generate a love of place and rootedness that is so important in our world today. "It changes the way you see things and you begin to understand how other people in different regions and continents think and how their lives are different; yet, quite the same as ours, with the same struggles and family issues" (male, Honduras, 2006).

Managing this kind of tension demands that administrators be creative and requires building a pedagogy that is "immersed, immediate, emotional, and interactive. Good global learners, it turns out, actually have much in common with good farmers. To be successful, both must practice smallscale immersion, intimate involvement, extended commitment, appropriate (cognitive) tools, humility, deep caring, careful observation, detailed knowledge, accurate recording, proper discipline, and ongoing assessment" (Slimbach, 2011, p. 21).

\section{Long-term Impacts of the Study Abroad Experience}

The last question examined in the interview portion of the study related to the longer term impacts of the study abroad experience on respondents. Results of the content analysis of these interviews reveal the overwhelmingly positive benefits felt by respondents following their semesters abroad. Although some respondents talked about how difficult the experience was at times, no one spoke of negative impacts of the experience, only the overall positive impacts they experienced. Overall benefits were grouped into either personal or professional benefits and then major themes were identified.

Themes related to personal benefits included: global awareness, maturity, self-confidence, and accomplishment. As one female respondent (2005) stated "there's literally not a day that goes by, even three or four years later, that I don't think about my experiences in France.... I can't explain it, but something in me fundamentally changed because of my experiences abroad.... I can't think of a single area of my life that my semester abroad hasn't touched in some way. I can't filter it down. It's been such an enormous impact." Likewise a male counterpart (2005) who studied in Honduras noted "I'd say, when I look back at my career, I think of my study abroad experiences as the total highlight where I grew the most, learned the most and experienced the biggest life changing events."

Themes related to the professional benefits of studying abroad included impacting one's career choice or major as well as being a resume builder. Several students described the impact of their semester abroad on specific career choices, as one female respondent (2006) noted "I ended up doing my student teaching in Chicago and in a Hispanic neighborhood there, I worked primarily with kids from Mexico and I don't know that I would have done that if I hadn't gone abroad. Now I have accepted a position with Teach for America, and I am headed down to the Rio Grande Valley in Texas, so I'll be doing that same kind of work, and I feel like going abroad to Honduras prepared me for that."

Similarly, one male student (2005) who studied in Honduras, recorded that his experience abroad provided a big boast to his medical school application. "Through medical school interviews it was a big plus to see that I've traveled all over the world and have a good foundation in 
communicating with people different from me. And especially for medical school where communication is so important between doctors and patients they really want to see that I can relate to people different from me."

The overwhelmingly-positive responses garnered from these interviews was confirmed in the online survey where $67.2 \%$ of respondents called their study abroad experience "excellent" and another $27.0 \%$ deemed it "good"). The overall results of this study also seemed to demonstrate a realization of the formative nature of the experience. As one female respondent (2005) put it, "I don't think any single semester was a formational to me as my semester in France...it was truly life-changing!"

\section{Implications for Further Study}

Results of this study collaborate much of the work of previous studies relating to the positive, long-term impacts of studying abroad. In addition, this study found several connections between local civic engagement and studying abroad: this is encouraging, while also pointing out the need for continued research to understand the factors that enhance the studying abroad experience and the long-term impact of such experiences on participants. Specifically this study highlighted the need to address such issues as:

- Examining how the location of the semester abroad might impact participants differently. As Hutchins (1996) noted, the location of students' experiences abroad has a large influence on how the experience impacts them. The results of this study supports Hutchins claim; yet, much work is still needed in order to understand these differences. In addition, more work needs to be done to help potential students make personal decisions that recognize these differences.

- Examining the tensions identified in this study related to assisting students in balancing the internal dynamics of the study abroad group with the need to push themselves to engage the people and culture of the place they are studying. Similarly, practitioners need to identify best practices for encouraging a sense of place in participants, both for the place where they are studying as well as the places they will return to after the experience.

- Examining how such factors of gender, academic major, and length of time removed from the semester abroad impacts the experience. Of particular interest should be attempting to understand how gender affects the experience and how study abroad offices can do a better job communicating to men about the value of studying abroad.

- Examining the long-term impacts of study abroad. As previously stated, the literature is lacking in longitudinal research related to study abroad. This study is a step in that direction, yet due to the focus on one school, it is only one small piece of what is needed as study abroad professions move forward and attempt to design impactful programs.

It is evident from the research that studying abroad has a strong impact on students' lives. In the short-term, those effects are strikingly obvious both personally and professionally as the experience is emotionally fresh and students make decisions for their lives based on their recent experiences. However, there are also obvious positive long-term impacts from a semester abroad, both personal and professional. Understanding these impacts is important as study abroad professionals work to design programs, promote these programs, and justify their existence to college administrators in a time of shrinking resources. Just as Kipling's words in the opening paragraph of this article often 
entice student's to think about the possibilities, they should also challenge study abroad administrators to better understand the experience so that the hidden benefits can be better understood by all.

\section{References}

Akande, Y. (2000). Exploring the long-term impact of study abroad: A case study of 50 years of study abroad alumni. International Educator, 9(3), 12-17.

Allen, L.Q. (2010). The impact of study abroad on the professional lives of world language teachers. Foreign Language Annals, 43(1), 93-103.

Alred, G., and Bryan, M. (2002). Becoming an intercultural mediator: A longitudinal study of residence abroad. Journal of Multilingual and Multicultural Development, 23(5), 339-52.

Armstrong, G.K. (1984). Life after study abroad: A survey of undergraduate academic and career choices. The Modern Language Journal, 68(1), 1-6.

Bachner, D., and Zeutschel, U. (2009, Feb.). Long-term effects of international educational youth exchange. Retrieved from http://en.afs60.de/web/index.php?TID=94

Benson-Schrambach, B. (2009). Undergraduate study abroad as a tool for vocational discernment. Journal of Christianity and Foreign Languages, 10, 10-26.

Black, H.T., and Duhon, D.I. (2006). Assessing the impact of business study abroad programs on cultural awareness and personal development. Journal of Education for Business, 81(3), 140-44. doi:10.3200/JOEB.81.3.140-144

Carlson, J.S., and Widaman, K.F. (1988) The effects of study abroad during college on attitudes toward other cultures. International Journal of Intercultural Relations, 12.1, 1-18.

Dukes, R., Lockwood, E., Oliver, H., Pezalila, C., \& Wilker, C. (1994). A longitudinal study of a Semester at Sea voyage. Annals of Tourism Research, 21(3), 489-498.

Dwyer, M. (2004). Charting the impact of studying abroad. International Educator, 13(1), 14-20.

Gonyea, R.M. (2008). The impact of study abroad on senior year engagement. Association for the Study of Higher Education, Jacksonville, MI. Retrieved from

http://cpr.iub.edu/uploads/Gonyea_StudyAbroad.pdf

Hadis, B.F. (2005). Gauging the impact of study abroad: How to overcome the limitations of a single-cell design. Assessment and Evaluation in Higher Education, 30(1), 3-19.

Hammer, M., and Hansel, B. (2005). The educational results study: AFS internal descriptive report of the complete findings. Retrieved from http://74.52.0.194/downloads/files/EducationalResults-Report-Final.pdf

Hansel, Bettina (2008). AFS long term impact study: Report 2. Retrieved from AFS International website: http://www.afs.org/downloads/files/Report_2_Long_Term_Impact.pdf

Hutchins, Marsha Mitchell (1996). International education study tours abroad: Students' professional growth and personal development in relation to international, global, and intercultural perspectives. Retrieved from OhioLINK website:

http://etd.ohiolink.edu/view.cgi?acc_num=osu1225391264.

Juhasz, A.M, and Walker, A.M. (1987). The impact of study abroad on university students' perceptions of self. Retrieved from http://www.eric.ed.gov/ 
Kitsantas, A. (2004). Studying abroad: the role of college students' goals on the development of cross-cultural skills and global understanding. College Student Journal, 38(3), 441+. Retrieved from Academic OneFile database. (A123321904)

Nash, D. (1976). The personal consequences of a year of study abroad. Journal of Higher Education, 42(2), 191-203.

Paige, R.M., Fry, G.W., LaBrack, B., \& Stallman, E.M. (2009). Study abroad for global engagement: Results that inform research and policy agendas. Conference presentation, Forum on Education Abroad Conference, Portland, OR.

Paige, R.M., Fry, G.W., Stallman, E.M., Josic, J., \& Jon, J.E. (2009). Study abroad for global engagement: The long-term impact of mobility experiences. Intercultural Education, S29-S44. doi:10.1080/14675980903370847.

Slimbach, R. (2011). The Fate of Civilization and the Future of Study Abroad: Lessons from a Kentucky Farmer. Carlisle, PA: The Forum on Education Abroad 